\title{
Opportunistic screening for alcohol use disorders in primary care: comparative study
}

Simon Coulton, Colin Drummond, Darren James, Christine Godfrey, J Martin Bland, Steve Parrott, Timothy Peters, on behalf of the Stepwice Research Team

\begin{abstract}
Objective To evaluate the efficacy and relative costs of different screening methods for the identification of alcohol use disorders in an opportunistic screening programme in primary care in the United Kingdom.

Design Comparative study.

Setting Six general practices in south Wales.

Participants 194 male primary care attendees aged 18 or over who completed an alcohol use disorders identification test (AUDIT) questionnaire.

Main outcome measures Scores on alcohol use disorders identification test and measures of $\gamma$-glutamyltransferase, aspartate aminotransferase, per cent carbohydrate deficient transferrin, and erythrocyte mean cell volume. Hazardous alcohol consumption, weekly binge consumption, and monthly binge consumption were ascertained using the time line follow back method over the previous 180 days. Alcohol dependence was determined using the Diagnostic and Statistical Manual of Mental Disorders, fourth edition. Unit costs were established from published resource references and from actual costs of analysing the biochemical tests.

Results A significant correlation was observed between alcohol consumption and score on the alcohol use disorders identification test (Pearson's correlation coefficient $r=0.74$ ) and measures of $\gamma$-glutamyltransferase $(r=0.20)$ and per cent carbohydrate deficient transferrin $(r=0.36)$ but not aspartate aminotransferase $(\mathrm{r}=0.08)$ or erythrocyte mean cell volume $(r=0.02)$. The alcohol use disorders identification test exhibited significantly higher sensitivity, specificity, and positive predictive value than all of the biochemical markers for hazardous consumption $(69 \%, 98 \%$, and $95 \%)$, weekly binge consumption (75\%, 90\%, and $71 \%)$, monthly binge consumption $(66 \%, 97 \%$, and $91 \%$ ), and alcohol dependence $(84 \%, 83 \%$, and $41 \%)$. The questionnaire was also more cost efficient, with a lower cost per true positive for all consumption outcomes.

Conclusion The alcohol use disorders identification test questionnaire is an efficient and cost efficient diagnostic tool for routine screening for alcohol use disorders in primary care.
\end{abstract}

\section{Introduction}

The prevention of alcohol related morbidity and mortality is a key priority of the UK government's health strategy. ${ }^{1}$ However, alcohol consumption in men and the proportion drinking above recommended "safe levels"-drinking in excess of 21 units of alcohol in any one week-has remained constant for over a decade, with increases in some subgroups. ${ }^{1}$ Furthermore, evidence is emerging that the incidence of binge alcohol consumption (consuming more than the daily recommended safe level in a single episode) is increasing in the general population. ${ }^{1}$ Excessive alcohol consumption has an important effect on individuals and society, imposing a major financial burden on the NHS. ${ }^{23}$ An estimated $20 \%$ of hospital inpatients have some form of alcohol related problem, although few seek treatment. ${ }^{4}$

About $20 \%$ of all patients presenting to general practitioners in the United Kingdom consume alcohol at excessive levels, yet $98 \%$ of these are not identified in the general practice setting. ${ }^{5}$ Good evidence shows that brief interventions for excessive alcohol use, aimed at reducing consumption and subsequent alcohol related harm and dependence, are both clinically and cost effective $^{6-10}$ Primary care is viewed as the most promising location to offer brief interventions. ${ }^{11}$ To offer such interventions, however, general practitioners need access to screening instruments that are high in sensitivity and specificity, quick and easy to apply, and can be carried out at reasonable cost.

Several studies have questioned the value of measuring traditional biochemical markers of excessive alcohol consumption for screening in primary care, such as $\gamma$-glutamyltransferase, aspartate aminotransferase, erythrocyte mean cell volume, and per cent carbohydrate deficient transferrin..$^{12}{ }^{13}$ The alcohol use disorders identification test (AUDIT) is a 10 item questionnaire specifically developed for use as a short screening instrument for the identification of hazardous, harmful, or dependent alcohol users. ${ }^{14}{ }^{15}$ A detailed receiver operating characteristic analysis of the screening properties of the questionnaire, $\gamma$-glutamyltransferase, aspartate aminotransferase, erythrocyte mean cell volume, and per cent carbohydrate deficient transferrin has not previously been undertaken in a primary care population in the United Kingdom.

We evaluated the sensitivity, specificity, and positive predictive value of the alcohol use disorders identification test and biochemical markers in the context of an opportunistic screening programme in primary care. We also carried out an economic analysis to establish the relative costs per true positive for each of the screening methods.

\section{Methods}

Our study was carried out before we embarked on a randomised controlled trial evaluating the effectiveness and cost effectiveness of stepped care interventions for alcohol use disorders in primary care. ${ }^{16}$ Research nurses asked male attendees in primary care to complete an alcohol use disorders identification test questionnaire embedded within a general lifestyle questionnaire 
while awaiting appointments in six participating general practices in south west Wales.

All patients, irrespective of score, were informed of the study and invited to take part in a more detailed assessment. Those patients who consented to the detailed assessment were interviewed by a researcher in the practice who assessed frequency and quantity of alcohol use in the previous 180 days using the time line follow back method. ${ }^{17}$ The researcher was blind to the patient's score. This method was used to establish the number of weeks in the previous 180 days the patient had exceeded the "safe level" of alcohol consumption (greater than 21 units of alcohol in any one week) and the frequency with which the patient engaged in binge alcohol consumption (greater than eight units of alcohol in any one day) in the past 180 days. This was used as a criterion for hazardous and binge alcohol consumption and is inclusive of harmful alcohol consumption and dependence.

The researcher established a diagnosis of alcohol dependence according to the Diagnostic and Statistical Manual of Mental Disorders, fourth edition, by administering the alcohol dependence element of the short form composite international diagnostic interview. ${ }^{18}$ Blood samples were then taken from each patient by venepuncture. Analysis of $\gamma$-glutamyltransferase, aspartate aminotransferase, and per cent carbohydrate deficient transferrin was carried out at the Department of Clinical Biochemistry, King's College, London, and analysis of erythrocyte mean cell volume was carried out at the Department of Haematology, Singleton Hospital, Swansea. Blood tests were carried out blind to the patient's score on the alcohol use disorders identification test.

\section{Instruments}

The time line follow back method is a reliable and valid method for deriving quantity and frequency of alcohol consumption in clinical and non-clinical populations. ${ }^{17}$ The method is completed by a trained researcher and takes on average 45 minutes to complete. The quantity and frequency of alcohol consumption is standardised into units of ethanol consumption and can be utilised as either continuous or categorical values.

The alcohol use disorders identification questionnaire is a 10 item self completed questionnaire that addresses frequency of alcohol consumption, alcohol related problems, and dependence symptoms. ${ }^{414}$ The questionnaire takes on average three minutes to complete and was embedded in a general lifestyle questionnaire to reduce the patient perceived threat. Each item is scored from 0-4. The overall score- - the sum of responses to each of the 10 questions-ranges from $0-40$. A score of 8 or more indicates hazardous alcohol consumption and has high levels of sensitivity (92\%) and specificity (94\%) for identifying alcohol use disorders. ${ }^{15}$

The alcohol dependence section of the short form composite international diagnostic interview ${ }^{18}$ is a valid and reliable method for the diagnosis of alcohol dependence as classified by the Diagnostic and Statistical Manual of Mental Disorders, fourth edition. The instrument is administered by a trained researcher and assesses seven symptoms of alcohol dependence: role interference, use in hazardous situations, emotional and psychological problems, urge to consume alcohol, increasing recovery time, consuming more than intended, and increasing consumption to maintain effect. The instrument is scored by summing individual responses to all items, and a score of 3 or more indicates alcohol dependence.

Biochemical markers of alcohol use are widely used indicators of alcohol use disorders in general practice. They measure indirect consequences of alcohol consumption. Research has questioned the sensitivity and specificity of blood measures in screening for alcohol use disorders. ${ }^{19}$ $\gamma$-glutamyltransferase is used clinically as a measure of non-specific liver toxicity, and serum $\gamma$-glutamyltransferase levels increase with exposure to alcohol. The normal reference range for $\gamma$-glutamyltransferase is $0-55 \mathrm{IU} / 1$ for men. The sensitivity and specificity of $\gamma$-glutamyltransferase varies depending on the clinical population, with lower sensitivity and specificity in general practice populations than in alcohol inpatient populations. ${ }^{13}$ The reference range for aspartate aminotransferase is 10-50 IU/1 in men. Increased levels are an indicator of hepatocyte damage and have been found associated with alcohol consumption in usually healthy populations. ${ }^{13}$ Aspartate aminotransferase has been found to be less sensitive than $\gamma$-glutamyltransferase in alcohol inpatient populations. ${ }^{19}$ Per cent carbohydrate deficient transferrin measures the ratio of carbohydrate deficient transferrin to total transferrin levels in serum and is considered to be more reliable than absolute levels of carbohydrate deficient transferrin because it addresses differences in total transferrin within individuals. Per cent carbohydrate deficient transferrin beyond the normal reference range for men $(>2.5 \%)$ better detects chronically heavy consumers of alcohol than infrequent hazardous consumers and is more specific than $\gamma$-glutamyltransferase or aspartate aminotransferase. ${ }^{20}$ Erythrocyte mean cell volume measures the mean volume of erythrocytes and has been recognised as increasing with excessive alcohol use. Results beyond the normal reference range of greater than $95 \mathrm{fl}$ have been found to have a relatively high specificity but low sensitivity for excessive alcohol use in general practice settings. ${ }^{13}$

\section{Statistical analysis}

We compiled and analysed the results using SPSS v11 and Stata 8 . As the patients were stratified by whether their test score was less than 8 or greater than or equal to 8 , with different sampling fractions in the two strata, stratification was allowed for in the analysis using the svy commands of Stata. We used correlation after applying normalising transformations to compute linear associations between quantity of alcohol consumed, standard drinks consumed per drinking day and test score, $\gamma$-glutamyltransferase, aspartate aminotransferase, per cent carbohydrate deficient transferrin, and erythrocyte mean cell volume. The ability of tests to predict alcohol consumption was tested by logistic regression. We explored the accuracy of the tests in identifying hazardous alcohol consumption, weekly or monthly binge consumption, and alcohol dependence by constructing receiver operating characteristic curves on the basis of all possible continuous values of the test results. This was done by expanding the sample to give true proportions in each stratum. We investigated the accuracy of each test method in each scenario by the calculation of sensitivity, specificity, and positive and negative predictive values.

We carried out an economic analysis of each screening method by establishing the unit cost of each method and establishing a cost per true positive for each screening method.

\section{Results}

Overall, 1794 men were consecutively approached in six general practices in south west Wales and completed the alcohol use disorders identification test questionnaire. Of these, 447 (24.9\%) were positive for alcohol use disorders and 112 (25\% of patients with a positive test result) agreed to take part. We randomly sampled, stratified by practice, 450 of the 1347 patients with a nega- 
Table 1 Personal and alcohol use variables in 194 male attendees in primary care. Values are numbers (percentages) unless stated otherwise

\begin{tabular}{|c|c|c|c|}
\hline Variables & $\begin{array}{c}\text { All patients } \\
(\mathrm{n}=194)\end{array}$ & $\begin{array}{l}\text { Patients with positive } \\
\text { AUDIT result ( } n=112)\end{array}$ & $\begin{array}{l}\text { Patients with negative } \\
\text { AUDIT result ( } n=82 \text { ) }\end{array}$ \\
\hline \multicolumn{4}{|l|}{ Personal variables } \\
\hline $\begin{array}{l}\text { Mean (range) age } \\
\text { (years) }\end{array}$ & $\begin{array}{c}46.2 \\
(18.3-80.9) \\
\end{array}$ & 42.8 (18.3-75.3) & $50.9(18.7-80.9)$ \\
\hline \multicolumn{4}{|l|}{ Marital status: } \\
\hline $\begin{array}{l}\text { Married or } \\
\text { cohabiting }\end{array}$ & $121(62)$ & $61 \quad(54)$ & 60 (73) \\
\hline $\begin{array}{l}\text { Divorced or } \\
\text { separated }\end{array}$ & $2(1)$ & $1(1)$ & $1(1)$ \\
\hline $\begin{array}{l}\text { Single, in } \\
\text { relationship }\end{array}$ & $21(11)$ & $19(17)$ & $2(2)$ \\
\hline $\begin{array}{l}\text { Single, not in } \\
\text { relationship }\end{array}$ & $40(21)$ & $30(27)$ & $10(12)$ \\
\hline Missing data & $10(5)$ & $1(1)$ & $9(11)$ \\
\hline \multicolumn{4}{|l|}{ Alcohol use variables } \\
\hline $\begin{array}{l}\text { Mean (range) drinks } \\
\text { per drinking day } \\
\text { (last } 180 \text { days) } \\
\end{array}$ & $10.4(0-53.0)$ & $14.0(2.4-53.0)$ & $5.2(0-20.5)$ \\
\hline $\begin{array}{l}\text { Percentage days } \\
\text { abstinent (last } 180 \\
\text { days) }\end{array}$ & $52.3(0-100.0)$ & $37.6(0-96.7)$ & $73.2(0-100.0)$ \\
\hline $\begin{array}{l}\text { Abstinent (last } 180 \\
\text { days) }\end{array}$ & $4(2)$ & 0 & $4(5)$ \\
\hline \multicolumn{4}{|l|}{$\begin{array}{l}\text { Frequency of binge } \\
\text { consumption: }\end{array}$} \\
\hline Never & $39(20)$ & $4(4)$ & $35(43)$ \\
\hline Less than monthly & $34(18)$ & $6(5)$ & $28(34)$ \\
\hline Monthly & $29(15)$ & $23(21)$ & $6(7)$ \\
\hline Weekly & $73(38)$ & $63(56)$ & $10(12)$ \\
\hline Daily or almost daily & $15(8)$ & $15(13)$ & 0 \\
\hline Missing data & $4(2)$ & $1(1)$ & $3(4)$ \\
\hline Hazardous alcohol use & $121(62)$ & $112(100)$ & $9(11)$ \\
\hline Alcohol dependent & $50(26)$ & $50(45)$ & 0 \\
\hline
\end{tabular}

AUDIT=alcohol use disorders identification test.

tive result, of whom $82(18 \%$ of patients with a negative result sampled) agreed to take part in the study. Patients with a negative test result who did or did not take part in the study showed no significant difference in age $(50.3 v 51.0 ; \mathrm{P}=0.18)$ or test score (3.53 $v 3.78 ; \mathrm{P}=0.28)$. Patients with a positive test result who did or did not take part in the study showed no significant difference in age $(43.1 v 37.4 ; \mathrm{P}=0.27)$ or test score $(13.5 v 12.0 ; \mathrm{P}=0.06)$.

The average age was 46.2 years (range 18.1-80.9 years). The majority of patients were married $(63 \%)$ and in employment $(58 \%)$. Fifty patients $(26 \%)$ fulfilled the criteria for alcohol dependence according to the Diagnostic and Statistical Manual of Mental Disorders, fourth edition, 121 (62\%) fulfilled the criteria for hazardous alcohol consumption, $117(60 \%)$ engaged in binge alcohol consumption at least monthly, and $4(2 \%)$ were abstinent. Table 1 lists the personal and alcohol consumption variables for the patients.

Using the sample to estimate the prevalence of drinking behaviours in the general practice population, the prevalence of hazardous alcohol consumption was 34\% (95\% confidence interval $28 \%$ to $40 \%$ ), monthly binge consumption $35 \%$ (29\% to $42 \%$ ), weekly binge consumption $24 \%$ (19\% to $29 \%$ ), and alcohol dependence $12 \%$ (9\% to $16 \%)$.

Significant correlations were found between alcohol consumption, measured as number of standard drinks consumed per drinking day (standard drink equates to $8 \mathrm{~g}$ of ethanol) over the previous 180 days, and alcohol use disorders identification test score (Pearson's correlation coefficient $\mathrm{r}=0.74 ; \mathrm{P}<0.001$ ), $\gamma$-glutamyltransferase $(\mathrm{r}=0.20 ; \mathrm{P}=0.04)$, and per cent carbohydrate deficient transferrin $(\mathrm{r}=0.36 ; \mathrm{P}<0.001)$ but not aspartate aminotransferase $(\mathrm{r}=0.03 ; \mathrm{P}=0.7)$ or erythrocyte mean cell vol- ume $(r=0.02 ; \mathrm{P}=0.9)$. Screening characteristics of the questionnaire and biochemical markers were tested against the criteria for hazardous alcohol consumption, monthly binge consumption, weekly binge consumption, and alcohol dependence through the construction of receiver operating characteristic curves on the basis of all possible continuous values of the test results (table 2 and figure) and the calculation of areas under the curve. The questionnaire was clearly better than any of the biochemical predictors and had a highly significant relation with alcohol consumption for all classifications. None of the significant biochemical predictors remained significant after controlling for questionnaire score. The questionnaire score also produced far higher areas under the receiver operating characteristic curve than any of the biochemical markers for all classifications. The questionnaire had areas under the receiver operating characteristic curve of 0.94 to 0.96 for all classifications, close to the maximum area of 1.00 for a perfect test, whereas only per cent carbohydrate deficient transferrin produced any area above 0.70 , and aspartate aminotransferase produced some areas in the region of 0.50 , as would be expected for a test unrelated to the outcome.

The questionnaire score cut-off of 8 or more had moderate sensitivity (69\%) for identifying hazardous alcohol consumption, with high specificity (98\%) and positive predictive value (95\%). The questionnaire performed almost as well in identifying monthly binge consumption, although its sensitivity, specificity, and positive and negative predictive values were all slightly lower. For weekly binge consumption the specificity fell to $90 \%$ and positive predictive value fell correspondingly, although the sensitivity increased to $75 \%$. For alcohol dependence, sensitivity was highest at $84 \%$, but specificity was lowest at $83 \%$, and the positive predictive value fell to $41 \%$. Negative predictive value was highest for this classification, rising to $97 \%$. Hence a positive questionnaire score is a good indication of hazardous alcohol consumption and a negative score is a good indication of no alcohol dependence.

Producing a copy of the alcohol use disorders identification test questionnaire embedded within a general lifestyle questionnaire cost $10 \mathrm{p}$, and administering and analysing the questionnaire took five minutes of practice nurse time. Using 2000-1 prices, the cost of five minutes of practice nurse advice was $£ 1.10$ (including salary, employer's national insurance and superannuation contributions, and a management overhead of $8 \%$ of the salary cost). We also added the cost of premises, at $50 \mathrm{p} / \mathrm{m}^{2} / \mathrm{h}$. Assuming that a room measured $12 \mathrm{~m}^{2}$ the cost of screening in such premises was $50 \mathrm{p}$ per patient. Therefore the total cost of administering the test was estimated at $£ 1.70$ per patient. The cost of taking and analysing the biochemical markers was estimated using a standard cost of venepuncture of $£ 9.00,{ }^{21}$ using $2000-1$ prices, divided by the number of tests $(n=4)$ derived from a single sample and the real cost of analysis carried out in the laboratories taking part in the study. This gave a cost associated with each blood test of $£ 5.25$ for $\gamma$-glutamyltransferase and aspartate aminotransferase, $£ 27.25$ for per cent carbohydrate deficient transferrin, and $£ 8.25$ for erythrocyte mean cell volume.

The alcohol use disorders identification test questionnaire had the lowest costs associated with administration and interpretation. Analysis of costs per true positive for hazardous, monthly binge, weekly binge, and dependent consumption indicate that the test is the most cost efficient screening method for all these categories of consumption. Table 3 shows the full costs for screening 1000 men. 
Table 2 Area under receiver operator curve, sensitivity, specificity, positive predictive value, and negative predictive value of alcohol use disorders identification test (AUDIT), $\gamma$-glutamyltransferase (GGT), per cent carbohydrate deficient transferrin (\%CDT), aspartate aminotransferase (ASAT), and erythrocyte mean cell volume (MCV) for hazardous alcohol use, monthly binge consumption, weekly binge consumption, and dependence in 194 male attendees in primary care

\begin{tabular}{|c|c|c|c|c|c|c|c|}
\hline Variable & $\begin{array}{l}P \text { value for logistic } \\
\text { regression }\end{array}$ & $\begin{array}{c}\text { P value after } \\
\text { controlling for AUDIT } \\
\text { score* }\end{array}$ & Area under curve & $\begin{array}{l}\text { Sensitivity \% (95\% } \\
\text { Cl†) }\end{array}$ & $\begin{array}{c}\text { Specificity } \%(95 \% \\
\text { CI†) }\end{array}$ & $\begin{array}{l}\text { Positive predictive } \\
\text { value } \%(95 \% \mathrm{Cl}) \text { ) }\end{array}$ & $\begin{array}{l}\text { Negative predictive } \\
\text { value } \%(95 \% \mathrm{Cl} \dagger)\end{array}$ \\
\hline \multicolumn{8}{|c|}{ Hazardous alcohol use: } \\
\hline AUDIT $(\geq 8)$ & $<0.001$ & - & 0.94 & 69 (57 to 81) & 98 (97 to 100) & 95 (91 to 99) & 86 (78 to 94$)$ \\
\hline GGT $(>55 \mathrm{IU} / \mathrm{I})$ & 0.06 & 0.01 & 0.64 & 37 (26 to 47$)$ & 72 (62 to 83 ) & 41 (28 to 54) & 69 (61 to 77$)$ \\
\hline ASAT (>50 IU/l) & 0.09 & 0.3 & 0.53 & 20 (11 to 29$)$ & 80 (71 to 89$)$ & 34 (19 to 50$)$ & 66 (59 to 73 ) \\
\hline$\%$ CDT $(>2.5 \%)$ & $<0.001$ & 0.7 & 0.68 & 47 (36 to 58$)$ & 71 (60 to 82) & 46 (34 to 58 ) & 72 (64 to 80$)$ \\
\hline MCV ( $\geq 95 \mathrm{fl})$ & 0.03 & 1.0 & 0.62 & 32 (21 to 43) & 71 (60 to 82) & 36 (23 to 50$)$ & 67 (59 to 74) \\
\hline \multicolumn{8}{|c|}{ Monthly binge consumption: } \\
\hline AUDIT $(\geq 8)$ & $<0.001$ & - & 0.96 & 66 (54 to 78 ) & 97 (95 to 99) & 91 (86 to 97) & 84 (76 to 92) \\
\hline GGT (>55 IU/I) & 0.06 & 0.08 & 0.62 & 42 (31 to 54$)$ & 76 (65 to 86 ) & 49 (34 to 63 ) & 71 (63 to 78 ) \\
\hline ASAT (>50 IU/I) & 0.08 & 0.3 & 0.55 & 26 (16 to 37 ) & 82 (73 to 92) & 45 (27 to 63) & 67 (60 to 74) \\
\hline$\%$ CDT $(>2.5 \%)$ & $<0.001$ & 0.3 & 0.73 & 59 (48 to 71$)$ & 76 (66 to 86 ) & 57 (44 to 71 ) & 78 (70 to 85$)$ \\
\hline MCV ( $\geq 95 \mathrm{fl})$ & 0.002 & 0.2 & 0.64 & 36 (24 to 47$)$ & 71 (60 to 82) & 40 (26 to 54$)$ & 67 (59 to 75) \\
\hline \multicolumn{8}{|c|}{ Weekly binge consumption: } \\
\hline AUDIT $(\geq 8)$ & $<0.001$ & - & 0.94 & 75 (61 to 90$)$ & 90 (88 to 93) & 71 (63 to 80$)$ & 92 (86 to 98 ) \\
\hline GGT (>55 IU/I) & 0.1 & 0.7 & 0.62 & 44 (32 to 57$)$ & 74 (64 to 83) & 35 (22 to 47) & 81 (75 to 86$)$ \\
\hline ASAT (>50 IU/I) & 0.004 & 0.2 & 0.49 & 29 (16 to 42$)$ & 82 (74 to 90$)$ & 34 (17 to 50$)$ & 78 (73 to 84$)$ \\
\hline$\%$ CDT (>2.5\%) & 0.002 & 0.7 & 0.72 & 61 (49 to 74 ) & 71 (62 to 81) & 41 (29 to 53) & 85 (80 to 91$)$ \\
\hline $\operatorname{MCV}(\geq 95 \mathrm{fl})$ & 0.04 & 0.5 & 0.59 & 31 (19 to 43$)$ & 69 (59 to 79$)$ & 24 (14 to 35$)$ & 76 (69 to 82 ) \\
\hline \multicolumn{8}{|l|}{ Alcohol dependence: } \\
\hline AUDIT $(\geq 8)$ & $<0.001$ & - & 0.94 & 84 (66 to 100) & 83 (81 to 86) & 41 (32 to 50) & 97 (94 to 100) \\
\hline GGT (>55 IU/I) & 0.5 & 0.004 & 0.59 & 32 (18 to 45$)$ & 69 (61 to 78$)$ & 13 (7 to 18$)$ & 88 (83 to 93) \\
\hline ASAT (>50 IU/I) & 0.4 & 0.04 & 0.50 & 19 (8 to 30$)$ & 80 (72 to 88$)$ & 12 (5 to 19$)$ & 88 (83 to 92) \\
\hline$\%$ CDT $(>2.5 \%)$ & 0.03 & 0.7 & 0.70 & 57 (41 to 73 ) & 68 (59 to 76) & 20 (12 to 28$)$ & 92 (88 to 96 ) \\
\hline MCV ( $\geq 95 \mathrm{fl})$ & 0.5 & 0.2 & 0.57 & 28 (15 to 41$)$ & 70 (61 to 79 ) & 11 (6 to 17) & 87 (83 to 93) \\
\hline
\end{tabular}

${ }^{*} A$ AUDIT $P<0.001$ in all regressions.

†Large sample estimates approximate for intervals including zero or $100 \%$.

\section{Discussion}

A simple screening instrument, the alcohol use disorders identification test (AUDIT) questionnaire, is an effective and cost efficient means for identifying hazardous and harmful drinkers in the primary care setting who could benefit from brief interventions. This contrasts with the current poor level of identification of alcohol use disorders by general practitioners. ${ }^{5}$ Overall, $25 \%$ of attendees who were screened scored positive on the test, an indication of the prevalence of alcohol use disorders in this population.

The alcohol use disorders identification test and levels of $\gamma$-glutamyltransferase and per cent carbohydrate deficient transferrin correlate with increasing alcohol consumption, but the test is a more efficient method for opportunistic screening in primary care than is measurement of $\gamma$-glutamyltransferase, aspartate aminotransferase, per cent carbohydrate deficient transferrin, and erythrocyte mean cell volume, in terms of sensitivity, specificity, positive predictive value, and cost. Routine screening in primary care should focus on the alcohol use disorders identification test questionnaire rather than biochemical markers of alcohol consumption. Biochemical markers of alcohol consumption often have short half-lives and require sustained consumption of alcohol at high levels. Because of this they fail to address the underlying longer term drinking behaviours that constitute hazardous and harmful alcohol consumption.

Owing to the detrimental effect of hazardous and harmful alcohol use on health, the widespread and routine implementation of intervention strategies is likely to have large benefits for public health and the health of the individual. A substantial evidence base exists for the efficacy of brief interventions in the primary care setting, including empirical studies ${ }^{22}{ }^{23}$ and systematic reviews. ${ }^{6-10}$ The most recent of these ${ }^{6}$ concluded that brief interventions are effective in reducing alcohol consumption 12 months after intervention, and a review carried out by the United States Preventative Taskforce concluded that "brief counselling interventions for risky/harmful alcohol use among adult primary care patients provide an effective component of a public health approach to reducing risky/harmful alcohol use." Another study questioned the feasibility of opportunistic screening in primary care for excessive alcohol use, ${ }^{24}$ but our study indicates that the alcohol use disorders identification test questionnaire, completed by the patient and scored by a practice nurse, produces more true positive cases of excessive alcohol use than the studies included within their meta-analysis. Successfully implementing brief interventions in part depends on identifying those patients who are most likely to benefit. The questionnaire is a clinically and cost efficient screening instrument for identifying patients who would benefit from brief interventions of proved effectiveness.

Primary care provides an excellent environment to combine opportunistic screening mechanisms and early intervention strategies to reduce the burden of excessive alcohol consumption on individuals, the NHS, and society. Further research is required to tackle the most effective means of implementing screening and brief intervention strategies within primary care.

We recognise that our study is limited by its focus on male attendees in primary care and that this limitation was structural rather than intentional. We would recommend a replication of the study with female attendees. We also recognise the possibility that those patients with a negative test score had misreported their alcohol consumption and were less likely to consent to a more detailed examination. Although evidence suggests that this 
form of bias is limited, ${ }^{11}$ our study was a pragmatic evaluation of screening instruments using real patients in a real NHS setting. In recruiting the sample for the study we stratified the population by status on the basis of alcohol use disorders identification test score. We took this stratification into account in the analysis.

Routine screening of all attendees in primary care should be considered throughout the NHS. This requires appropriate training, resources, and incentives for staff. Identifying those patients in primary care who are likely to benefit from brief interventions will help to achieve targets set out in the national harm reduction strategy for England.'

We thank those who contributed to the Stepwice project, including staff and patients at the six general practices that took part.

Contributors: SC, CD, DJ, CG, SP, and TP designed and carried out the study. SC and JMB carried out the statistical analysis. All authors commented on successive drafts of the manuscript and approved the final version for submission. SC and JMB are guarantors.

Funding: The study was funded as part of the stepped care treatment evaluation in primary care funded by the Welsh Office of Research and Develop-
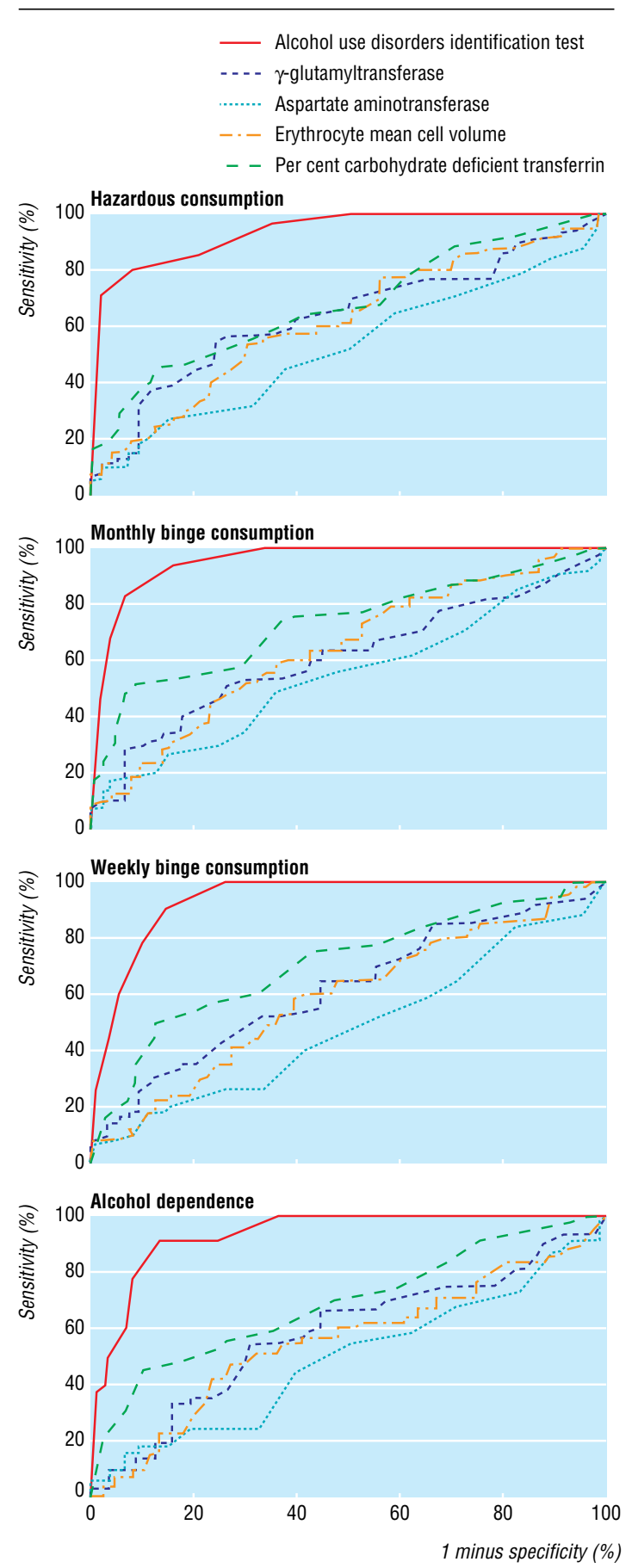

Receiver operating characteristic curve indicating screening properties of alcohol use disorders identification test, $\gamma$-glutamyltransferase, aspartate aminotransferase, per cent carbohydrate deficient transferrin, and erythrocyte mean cell volume for hazardous alcohol consumption, monthly binge consumption, weekly binge consumption, and alcohol dependence in 194 male attendees in primary care 
Table 3 Unit costs $(£)$ and cost per true positive for each screening test and outcome for 1000 male attendees in primary care

\begin{tabular}{|c|c|c|c|c|c|}
\hline Variable & $\begin{array}{l}\text { Alcohol use disorders } \\
\text { identification test }\end{array}$ & $\gamma$-glutamyltransferase & Aspartate aminotransferase & $\begin{array}{l}\text { Per cent carbohydrate } \\
\text { deficient transferrin }\end{array}$ & $\begin{array}{c}\text { Erythrocyte mean cell } \\
\text { volume }\end{array}$ \\
\hline \multicolumn{6}{|l|}{ Unit costs per test: } \\
\hline Printing costs & 0.10 & 0.00 & 0.00 & 0.00 & 0.00 \\
\hline Venepuncture & 0.00 & $2.25^{\star}$ & $2.25^{\star}$ & $2.25^{\star}$ & $2.25^{*}$ \\
\hline $\begin{array}{l}\text { Analysis and } \\
\text { interpretation }\end{array}$ & $1.60 \dagger$ & $3.00 \ddagger$ & $3.00 \ddagger$ & $25.00 \ddagger$ & $6.00 \ddagger$ \\
\hline Total cost per test & 1.70 & 5.25 & 5.25 & 27.25 & 8.25 \\
\hline $\begin{array}{l}\text { Cost to screen } 1000 \\
\text { patients }\end{array}$ & 1700 & 5250 & 5250 & 27250 & 8250 \\
\hline \multicolumn{6}{|l|}{$\begin{array}{l}\text { Hazardous alcohol } \\
\text { consumption: }\end{array}$} \\
\hline $\begin{array}{l}\text { Expected number of true } \\
\text { positives }\end{array}$ & 236 & 126 & 69 & 162 & 109 \\
\hline Cost (£) per true positive & 7.19 & 41.82 & 76.47 & 168.16 & 75.42 \\
\hline \multicolumn{6}{|l|}{$\begin{array}{l}\text { Monthly binge } \\
\text { consumption: }\end{array}$} \\
\hline $\begin{array}{l}\text { Expected number of true } \\
\text { positives }\end{array}$ & 233 & 149 & 93 & 209 & 125 \\
\hline Cost per true positive & 7.30 & 35.13 & 56.49 & 130.26 & 65.98 \\
\hline \multicolumn{6}{|l|}{ Weekly binge consumption: } \\
\hline $\begin{array}{l}\text { Expected number of true } \\
\text { positives }\end{array}$ & 182 & 107 & 70 & 148 & 75 \\
\hline Cost per true positive & 9.35 & 48.89 & 75.32 & 183.68 & 109.58 \\
\hline \multicolumn{6}{|l|}{ Alcohol dependence: } \\
\hline $\begin{array}{l}\text { Expected number of true } \\
\text { positives }\end{array}$ & 103 & 39 & 24 & 70 & 34 \\
\hline Cost per true positive & 16.49 & 135.79 & 222.20 & 390.57 & 240.05 \\
\hline
\end{tabular}

${ }^{*}$ Cost includes nurse time, syringe, and bottle ${ }^{21}$ divided by number of tests derived from each sample. ${ }^{4}$

†Based on five minutes of practice nurse time (£1.10) and five minutes use of premises measuring $12 \mathrm{~m}^{2}$ at $£ 6 / \mathrm{h}$ (2000-1 prices). ${ }^{21}$

$\ddagger$ Analysis undertaken in laboratory (2000-1 prices).

ment. The authors have no connection with this organisation beyond the recipients of the original grant.

Competing interests: None declared.

Ethical approval: Brigend, Neath, Port Talbot, and Swansea local research ethics committee.

1 Prime Minister's Strategy Unit. Alcohol harm reduction strategy for England. London: Stationery Office, 2004

2 Royal College of Physicians. Alcohol-can the NHS afford it? London: RCP, 2003.

3 Maynard A, Godfrey C. Alcohol policy: evaluating the options. Br Med Bull 1994;50:221-30

4 Allen J, Reinert D, Volk R. The alcohol use disorders identification test: an aid to recognition of alcohol problems in primary care patients. Prev Med 2001:33:428-33.

5 Kaner E, Heather N, McAvoy B, Lock C, Gilvarry E. Interventions for excessive alcohol consumption in primary health care: attitudes and practices of English general practiioners. Alcohol Alcohol 1999;34:559-66.

6 Bertholet N, Dappen J, Wietlisbach V, Fleming M, Burnand B. Reduction in alcohol consumption by brief alcohol intervention in primary care: systematic review and meta-analysis. Arch Intern Med 2005;165:986-95.

7 Ballesteros J, Duffy JC, Querejeta I, Arino J, Gonzalez-Pinto A. Efficacy of brief interventions for hazardous drinkers in primary care: systematic review and meta-analysis. Alcohol Clin Exp Res 2004:28:608-18.

8 Whitlock EP, Polen MR, Green CA, Orleans T, Klein J. Behavioral counselling interventions in primary care to reduce risky/harmful alcohol use by adults: a summary of the evidence for the US Preventive Services Task Force. Ann Intern Med 2004;140:557-68.

\section{What is already known on this topic}

The use of biochemical markers in identifying patients consuming alcohol at excessive levels has been questioned

A recent study highlights the low level of identification of alcohol use disorders in primary care

\section{What this study adds}

A short, self completed instrument in primary care-the alcohol use disorders identification test questionnaireexhibited higher sensitivity, specificity, and positive predictive value, and cost less to apply than biochemical markers
9 Moyer A, Finney JW, Swearingen CE, Vergun P. Brief interventions for alcohol problems: a meta-analytic review of controlled investigations in treatment-seeking and non-treatment-seeking populations. Addiction 2002:97:279-92

10 Fleming MF, Mundt MO, French MT, Manwell LB, Stauffacher EA, Barry KL. Brief physician advice for problem drinkers: long-term efficacy and benefit-cost analysis. Alcohol Clin Exp Res 2002;26:36-43.

11 Deehan A, Templeton L, Taylor C, Drummond DC, Strang J. How do general practitioners manage alcohol misusing patients? Results from a national survey of GPs in England and Wales. Drug Alcohol Rev 1998;17:259-66.

12 Conigrave K, Davies P, Haber P, Whitfield J. Traditional markers of excessive alcohol use. Addiction 2003;98(suppl2):31-43.

13 Meerkerk G, Njoo K, Bongers I, Trienekens P, van Oeurs J. Comparing the diagnostic accuracy of carbohydrate-deficient transferrin, gammaglutamyltransferase and mean cell volume in a

14 Babor T, Grant M. From clinical research to secondary prevention: internationa collaboration in the development of the alcohol use disorders identification test. Alcohol Health Res World 1989:13(3).

15 Saunders JB, Aasland OG, Babor TF, de la Fuente JR, Grant M. Development of the alcohol use disorders identification test (AUDIT): WHO collaborative project on early detection of persons with harmful alcohol consumption-II. Addiction 1993;88:25-31.

16 Drummond C, James D, Coulton S, Parrott S, Baxter J, Ford D, et al. The effectiveness and cost-effectiveness of screening and stepped care interventions for alcohol use disorders in the primary care setting. Cardiff: Wales Office for Research and Development, 2004.

17 Sobell LC, Sobell MB. Timeline followback: a technique for assessing self-reported ethanol consumption. In: Allen J, Litten RZ, eds. Measuring alcohol consumption:psychosocial and biological methods. Totowa, NJ: Humana Press, 1992:41-72.

18 Nelson C, Kessler R, Mroczek D. Scoring the World Health Organization's composite international diagnostic interview. Geneva: WHO, 1998.

19 Aertgeerts B, Buntinx F, Ansoms S, Fevery J. Screening properties of questionnaires and laboratory tests for the detection of alcohol abuse or dependence in a general practice population. BrJ Gen Pract 2001;51:206-17.

20 Helander A, Carlsson A, Borg S. Longitudinal comparison of carbohydrate-deficien transferrin and gamma-glutamyl transferase: complementary markers of excessive alcohol consumption. Alcohol Alcohol 1996;31:101-7.

21 Netten A, Curtis L. Unit costs of social and health care. Canterbury: Personal Social Services Research Unit, 2002.

22 Anderson P, Scott E. The effect of general practitioners' advice to heavy drinking men. Br J Addict 1992;87:891-900.

23 Wallace P, Cutler S, Haines A. Randomized controlled trial of general practitioner intervention with excessive alcohol consumption. BMJ 1988;297:663-8.

24 Beich A, Thorsen T, Rollnick S. Screening in brief intervention trials targeting excessive drinkers in general practice: systematic review and meta-analysis. BMJ 2003;327:536. (Accepted 10 January 2006)

doi $10.1136 /$ bmj.38743.421574.7C

Department of Health Sciences, University of York, York YO10 5DD Simon Coulton senior research fellow

Christine Godfrey professor 
Research

J Martin Bland professor

Section of Addictive Behaviour, Division of Mental Health, St George's Hospital

Medical School, University of London, London SW17 0RE

Colin Drummond professor $7 \mathrm{XB}$

Darren James trainee clinical psychologist
Department of Clinical Psychology Training, Whitchurch Hospital, Cardiff CF14
Centre for Health Economics, Alcuin College, University of York Steve Parrott research fellow

Department of Biochemistry, King's College, University of London, London WC2R 2LS

Timothy Peters professor

Correspondence to: S Coulton sc21@york.ac.uk 